\title{
Understanding the flow of caved ore and its influence on ore recoveries and dilution in a block cave
}

\author{
T.G. Heslop Mine Geotechnics (WA) Pty Ltd, Australia
}

\begin{abstract}
Ore recovery and dilution are critical issues in the economic projections of block cave viability and ultimately the profits made by the mine. In planning and operating caving mines, numerical modelling techniques are increasingly used to model material flows in the feasibility and planning phases of the mine life, and to monitor draw down in the production phase. Not only are numerical modelling results strongly influenced by the assumed boundary conditions and material flow characteristics, the modelling techniques have limitations and may not reliably replicate the actual conditions in the cave. These include variations in material flow characteristics and the changes in these as the draw progresses. Any errors or biases in these assumptions can have a huge effect on economic projections and ultimately in the actual profitability of the mine. A sound understanding of the dynamic nature of draw mechanics is essential in both the appraisal of modelling results and in the formulation of draw control strategies for maximum recoveries.
\end{abstract}

In this paper the writer reviews material flow theories, the factors that influence the nature and direction of draw and discusses strategies that could assist in reducing dilution ingress from both theoretical and practical points of view. Recent experience and lessons from producing mines, marker migration monitoring and model tests are drawn on for this assessment.

\section{Introduction}

How wide does a drawpoint draw? The next question is: how does a drawpoint draw?

There have been many attempts to answer these questions ever since the first block cave over a hundred years ago at the Pewabic Mine, Michigan in 1898. The answers to these questions are important in the design of the extraction levels for maximum ore recovery and maximum stability, and designing draw control processes for excluding or minimising dilution. We probably still have not reached the answers yet, but we are learning and the time has come to summarise what we know and what we don't.

Much of what we know has come from physical models and observations of draw conditions in both block cave drawpoints and sublevel caving rings. Marker tests in sublevel caving rings have contributed greatly to our understanding of draw. A few block caving mines have yielded useful calibration data from back analysis of the appearance of natural geological marker horizons, or support materials left on an earlier extraction level in the material drawn. With the exception of these, block caving marker tests have contributed less to the art because of the difficulty of placing and recovering sufficient markers to understand the draw mechanisms. Numerical modelling is becoming increasingly capable of modelling draw realistically, but is not there yet for coarsely fragmented ore.

The three draw mechanisms that have received most attention in mines and research efforts in the past 50 years are:

- gravity flow in granular materials (also known as ellipsoids of draw)

- interactive draw

- void diffusion.

These mechanisms are not mutually exclusive. They may occur at the same time in different areas of a block cave or at different times in the life of a drawpoint. We need to identify the dominant mechanism in the block cave and when and where the other mechanisms will occur. The different mechanisms have differences in dilution ingress patterns as well as grade and tonnage predictions that affect the production forecasts and expectations in terms of ore recovery and grade. 
In preparing this paper, the writer has drawn heavily on a chapter that was to a large extent prepared by the writer for D.H. Laubscher's Block Caving Manual in 2000. This manual was prepared for the first International Caving Study (ICS) and the circulation of the manual was initially restricted to the participants of the ICS. It was subsequently expanded and published by E.T. Brown in his book, Block Caving Geomechanics, in 2003. In this paper the term 'interactive draw' is used to describe the interaction between drawpoints that have been moved some critical distance apart (as in Laubscher's Block Caving Manual). Bull and Page (2000) and later Guest (2007) have applied the term 'interactive' to two drawpoints placed in very close proximity so that their isolated draw zones materially interact. Milestones on the way to getting the answers include the following.

\subsection{Physical models}

1913 Model draw tests at Inspiration Consolidated Copper Co. to test the recoveries with drawpoint spacings at $1.9 \mathrm{~m}, 2.7 \mathrm{~m}$ and $3.8 \mathrm{~m}$ spacings with graduated material from fines to a scaled $750 \mathrm{~mm}$, a draw height of $21 \mathrm{~m}$ and capped with about $17 \mathrm{~m}$ waste.

$1945 \quad 1: 120$ scale model draw tests at Climax Molybdenum Mine, using crushed mineralised material as ore and sand and gravel as waste in the initial experiments, but to better mimic real conditions underground the 'ore' was consolidated with a gypsum based cement to produce boulders up to a scaled $9 \mathrm{~m}$ across (McNicholas et al., 1946).

1955-1965 The development of the theory of free flow of granular materials in bins and hoppers into the Ellipsoid of draw theory in block caving and sublevel cave mine by Janelid and Kvapil (1966). This theory was based on 2D observations of draw in sand models with a Perspex front.

1974-1980 The development of the interactive draw theory based on numerous tests in a sand-filled 1:100 scale 3D model with 50 drawpoints at Shabanie Mine by the writers, Giovani Marano and Dennis Laubscher (Marano, 1980; Heslop, 1983; Laubscher, 1994).

2000-2009 1:10 scale 3D sand box modelling identified interactive flow between adjacent drawpoints and isolated-interactive flow across major apices (Susaeta, 2004a, 2004b). This led to the development of the theory of gravity flow (the Fm model). Calibration drilling at El Teniente and confirmed this model and the importance of uniform draw. In the same period, Alfaro and Saavedra (2004) developed a predictive model for gravitational flow based on cellular automata with encouraging results. Castro et al. (2009) tested FlowSim another cellular automata programme for modelling draw and after calibration with actual draw data from Inca Oeste Norte-El Salvador the technique was used to simulate draw from the Esmeralda Sector of El Teniente which indicated that cellular automata (CA) may be used as a prediction tool to help in the design of drawpoint levels.

2004-2007 Large scale 3D modelling of draw through single and multiple drawpoints using crusher aggregates of various sizes and gradings at the Julius Kruttschnitt Mineral Research Centre (JKMRC) by Power (2004) and Castro (2007).

\subsection{Marker tests}

1969-1970 Marker experiments in sublevel caving rings at Grangesberg iron ore mine, which demonstrated asymmetrical draw bodies, and pulsating waste rock content in the tonnage drawn.

1980-1990 Full scale tracking of markers at King Mine in Zimbabwe reported by Bell in 1992, and similar marker experiments at El Teniente reported by Alvial in 1992, indicates inclined particle movement trajectories in block caves under the influence of side or differential vertical pressures.

1997-1998 Marker experiments in sublevel cave rings by Gustafsson (1998) at Kiruna that indicated irregular 'palm and finger' draw bodies. These marker tests were intended to investigate fluctuations in waste rock content in the ore recovered in sublevel cave rings. In considering the available computer modelling methods Gustafsson (1998) chose the stochastic void 
diffusion modelling approach that was originally developed by Jolley (1968), for its potential to incorporate a number of improvements which would better replicate the real draw phenomena revealed by the Kiruna marker tests.

2000-2004 Marker experiments at Ridgeway Mine by Power (2004) and at Perseverance Mine by Szwedzicki and Cooper (2007), demonstrated similar narrow irregular draw bodies in the drawing of sublevel caving rings. It should be noted that both mines use a forward dumped ring, and so shallow draw $(<3 \mathrm{~m})$ and run-up against the overhanging face can be expected.

\subsection{Computer modelling}

With the development of computer power over the last four decades, there was a matching development of computer software to model and analyse draw mechanisms, predict tonnages available for draw, track production and control draw-down process. There is an increasing range of stochastic, CA and discrete element modelling and analytical tools to help us understand draw processes and their use in mine planning and production scheduling applications. These modelling programmes are beyond the scope of this paper.

Gemcom's PCBC was developed in the early 1990s and was based on Laubscher's interactive draw guidelines. It has emerged as the most widely used draw modelling and controlling software. It is now used on $80 \%$ of block cave mines in one way or another. This code uses user-specified inter-column and interlayer mixing parameters and user-specified draw column profiles in its simulation of block cave draw down.

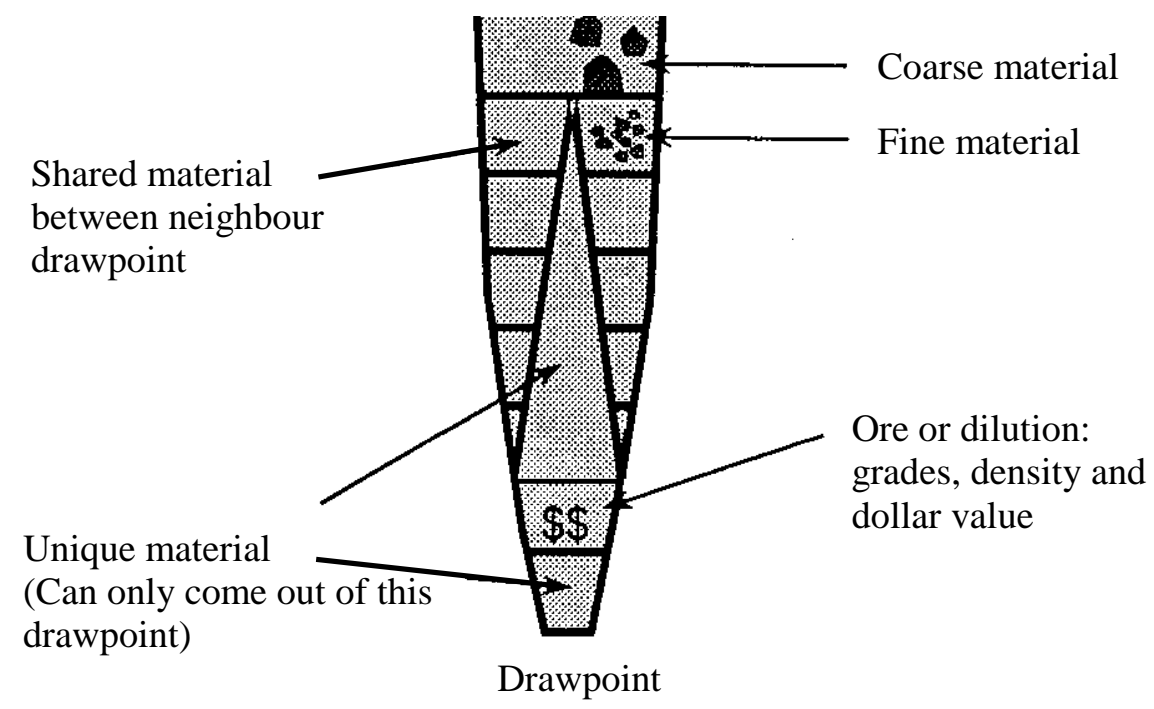

Figure 1 Illustration of the shared components of a draw column profile the mixing processes (after Diering, 2000) 


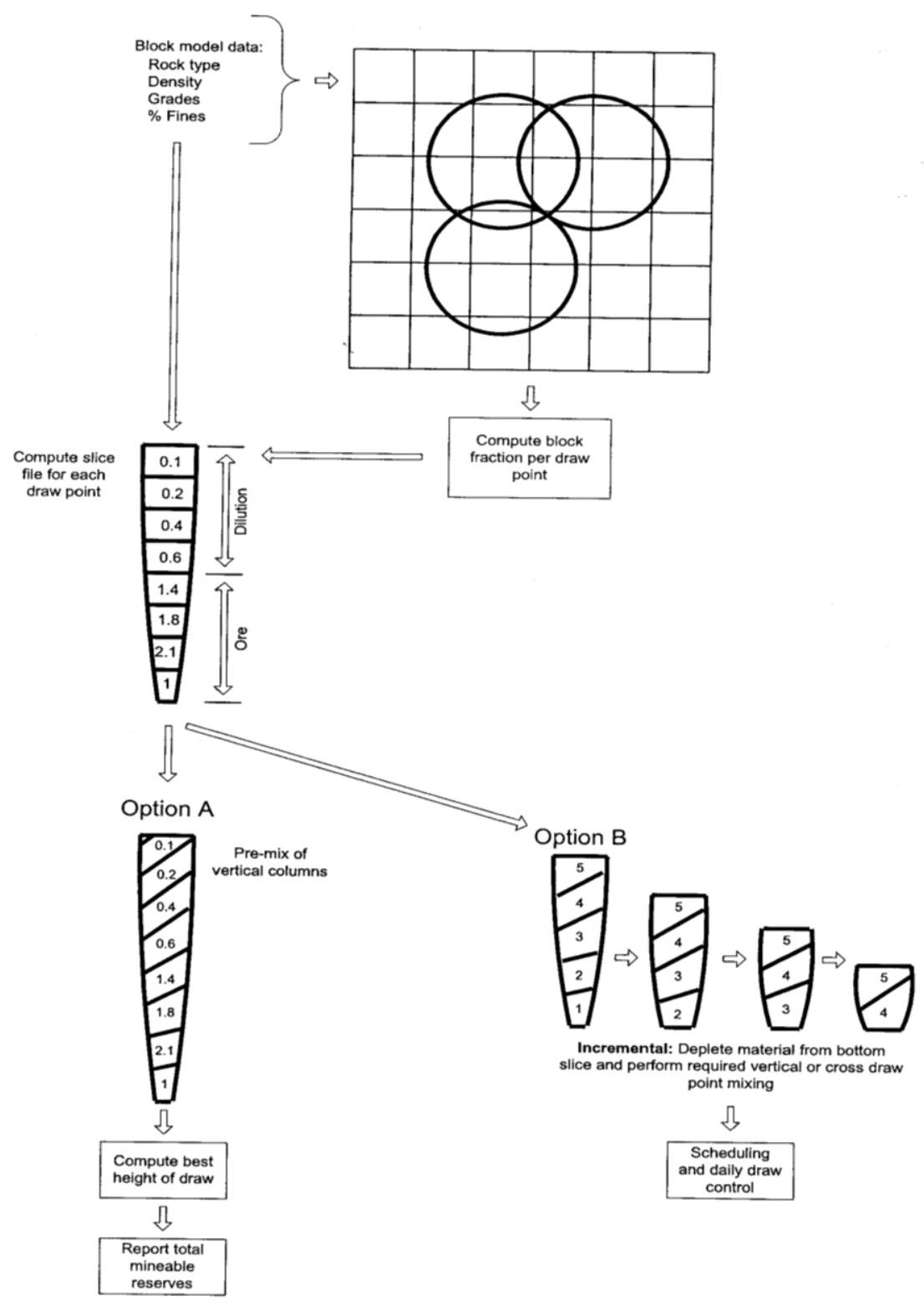

Figure 2 The overall flow chart for the processing of block model data final reserves or schedules with the vertical mixing stages (after Diering, 2000)

\section{Draw mechanisms}

From all this work, we know that there are three basic mechanisms of draw in the cave material:

- The first of these is the classical gravity flow (Janelid and Kvapil's (1966) 'ellipsoid of draw') in granular materials. When a single drawpoint is worked, particles within an ellipsoidal-like zone above the drawpoint flow under gravity towards the drawpoint, while the material outside this ellipsoid (the 'limit ellipsoid') remains static. Reasonably uniform draw can be achieved by close spacing of the drawpoints so that their ellipsoids of movement overlap.

- The second is 'interactive draw' which is a special case of classical gravity flow in which the pressures in the passive zones are sufficient to cause shear failure of the material and squeeze the passive zones between active drawpoints laterally into the live draw zones above the drawpoints being worked. The pressures are generated by overburden load plus a proportion of the weight of material within all the adjacent subsiding active draw zones which is transferred through friction to the surrounding passive material. 
- The third mode of flow is 'void diffusion' which occurs in coarser grained materials where transient voids or hang-ups form and collapse when drawn. The voids allow material to rill in from above or the sides and in so doing migrate up or laterally. Voids may coalesce before the arch forming the void collapses. It is replaced higher up by one or more smaller voids and the process repeats itself.

All three mechanisms have some similar characteristics, with a zone of mass flow or uniform draw down in the upper section of the cave and a lower zone of differential draw down and mixing.

A detailed review of these mechanisms is beyond the scope of this paper. The principles of these mechanisms probably are well known to almost all readers. All the writer intends to do in this paper is to discuss some emergent issues.

\subsection{Mass flow zone}

The mass flow zones in all draw mechanisms are similar with an orderly and uniform subsidence within the zone. This is the result of the overlap in the zone below the ellipsoids of draw in granular flow, or draw bodies in void diffusion, or the interaction between draw zones where these mechanisms are active. The particles are not greatly influenced by the rate of draw from individual drawpoints below, but may reflect steps defined by zones of drawpoints worked at higher rates. However, the uniform drawdown may be punctured by relatively small 'ratholes' or vortex-like subsidence zones where drawpoints have been worked in isolation or where a zone of highly mobile sheared material exists. Other than these small zones, there is no horizontal or vertical mixing and fine and coarse materials tend to subside at the same as the rate.

Material movement within the mass flow zone may not always be vertical, but may converge or diverge according to the shape of the cave, or in response to side pressures from sidewall shear failures on inwarddipping structures in the peripheries of the caved block. Flow trajectories also tend to be deflected towards lower density areas above zones of drawpoints being drawn at higher rates, or away from areas of higher pressures such as the areas of higher pressure due surface elevation differences.

\subsection{Gravity flow (ellipsoids of draw)}

The first of these flow mechanisms was extensively investigated in the early sand model experiments, usually small plexiglass or even glass-fronted sandboxes. Janelid and Kvapil (1966) interpreted the principles of 'gravity flow' through a single drawpoint from 2D model experiments. They have identified the characteristic ellipsoid of draw, limit ellipsoid and particle flow trajectories.

Numerous sand and aggregate model tests show us that the shape of the 'ellipsoid of draw' is not a perfect ellipsoid but more inverted tear shape. But by approximating it to an ellipsoid we can work out a range of parameters such as theoretical recoveries, dilution entry points, waste rock content of the ore flow, instantaneous grades, tonnage drawn cutoff points. These are all based on the shape of the ellipsoid as defined by its eccentricity or in more modern terms its isolated movement zone diameter (IMZ) or isolated draw zone diameter (IDZ).

The model work by Janelid and Kvapil (1966) has demonstrated that the eccentricity (or ellipse diameter) is dependent on a number of factors, including the height of draw, the width of the drawpoint or draw hole, the mean particle size across the draw column, drawing rate and compaction within the draw zone. Many of these will change during the life of the drawpoint, and so the IDZ diameter is not a single number but a range.

In block caving mine designs that are based on gravity flow, the drawpoints are spaced so that the limit ellipsoids are contiguous or overlap to some extent. When multiple partially overlapping drawpoints are worked at an even rate, there is a certain elevation where subsidence rates within the overlap zones equal the subsidence rates in the centres of the draw ellipsoids. This height has been called $h_{C}$ (the critical height of individual drawpoint influence - see Figure 3) by Janelid and Kvapil (1966). Above this height, subsidence is uniform and the ore-waste contact remains level as draw proceeds down to the $\mathrm{h}_{\mathrm{C}}$ when the interface comes under the influence of individual drawpoints. 


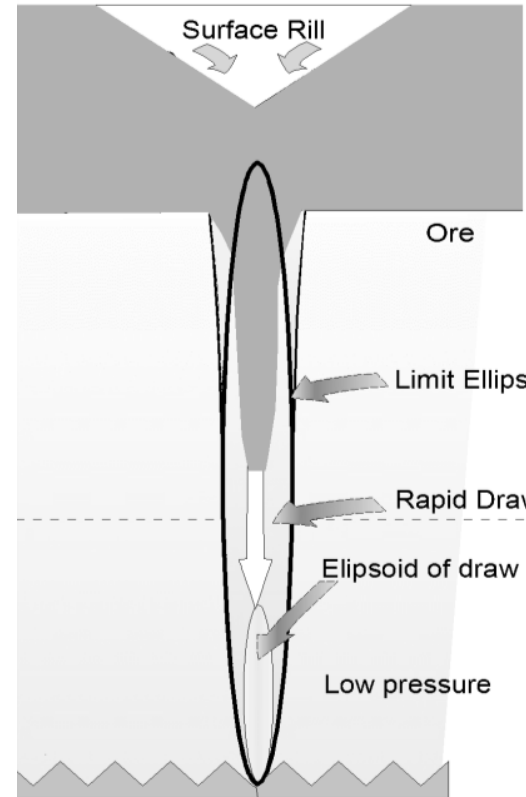

Figure 3 Granular flow mechanisms - material flow paths for drawpoints worked in isolation (left) where multiple drawpoints are closely spaced and their draw ellipsoids overlap and are drawn evenly (right)

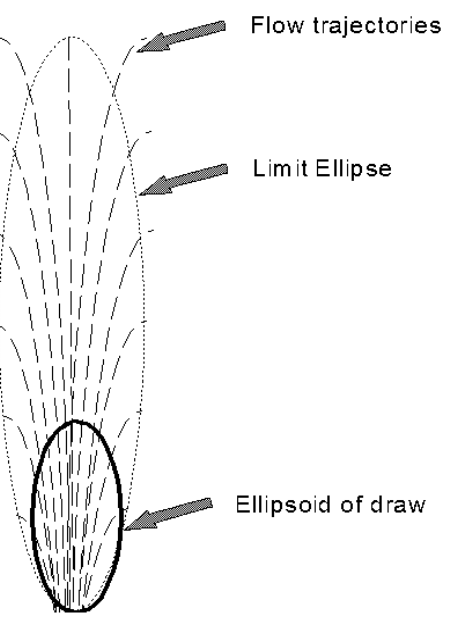

Figure 4 The 'gravity flow' ellipsoid of draw (the amount of material drawn out); the limit ellipsoid, i.e. the limit of disturbance when the ellipsoid of draw is withdrawn; and the particle flow trajectories (Janelid and Kvapil, 1966)

The critical issue in mine designs based on this mode of draw is diameter of the ellipsoid of draw or IDZ. Model tests by Janelid and Kvapil (1966) have demonstrated that the width (or eccentricity) of an ellipsoid of draw is dependent on a number of factors, increasing with the height of draw, the width of the drawpoint or draw hole, the mean particle size in the draw column, drawing rate and compaction within the draw zone. The effect of angles of internal friction was not investigated or reported in this paper.

\subsubsection{Gravity flow: implications for mine design and draw management}

1. The drawpoint spacing used in the design of an extraction level is critical. If the drawpoint spacing is too wide, there will be no overlap of the ellipsoids of movement and draw will be as for isolated drawpoints for each and every drawpoint. There will be consequential losses of ore between the 
draw columns and an early ingress of dilution. Drawpoints need to be spaced at less than the IDZ. For maximum overlap the drawpoint spacing needs to be 0.7 times the IDZ (this means over four times the number of drawpoints required for interactive draw).

2. The 1:30 scale model tests in the JKMRC large scale model by Power (2004) indicate that Laubscher's (1994) guidelines on the isolated draw zone diameters may be grossly underestimated. Further work on the influence of the angle of internal friction on the IDZ diameter is required (see further comments on interactive draw).

3. If drawpoints are sufficiently close for the overlapping of draw zones as in Figure 1, and even draw can be maintained from all drawpoints, then the dilution entry point may be as for interactive draw (depending on the ultimate height of draw say $70 \%$, compared with $30 \%$ for isolated draw).

4. Drawpoint spacings that are too close could cause coalescing of adjacent draw columns and draw in dilution very early with an attendant increase in unrecoverable ore.

5. To achieve uniform subsidence, it is not necessary to have concurrent draw in all drawpoints, but an even draw in small regular increments is required. If one drawpoint is worked at substantially higher rates than its neighbours, its draw ellipsoid will become much higher, similar to an isolated drawpoint in interactive draw, with the expected early ingress of dilution and ore losses.

6. The 'shared' zones in PCBC are very similar to the overlap zones in the gravity flow postulated by Janelid and Kvapil (1966) (Figure 1). With appropriate mixing input parameters, PCBC will probably be able to be used to calculate production tonnages and grade forecasts.

7. When the tonnage recovered from a drawpoint lags behind its neighbours, it should be remembered that those neighbours will have drawn ore from the draw of the slow column and less tonnage will be available from the slow drawpoint, while the neighbouring drawpoints will have gained tonnage. Attempting to catch up may introduce dilution early.

8. When a drawpoint is worked faster than its neighbours, it will behave like an isolated drawpoint and draw in material from the shared overlap zones of its neighbours. The height of remaining ore in the draw column will not be as high as the overdrawn tonnage may suggest. This is unless there has been piping or ratholes that have formed.

9. Recent model test work by Castro (2007) has shown that interactive draw does not occur - in tests on crushed aggregate with an internal friction angle of $41^{\circ}$ - and draw columns behave as isolated drawpoints. He demonstrated that the stresses that develop at the base of the model between drawpoints are insufficient to cause yield in the inter-drawpoint material. This is discussed further in interactive draw.

\subsection{Interactive draw}

Interactive draw mechanism was first recognised in tests in the large 3D sand model at Shabanie Mine in the mid 1970s. The model comprised a rigid steel bin with 50 holes in the base (representing drawpoints) and a removable side that could be removed in $300 \mathrm{~mm}$ high sections and an electric motor powered a system of rakes which could be set to draw the model material from the drawpoints at different rates. The base was equipped with 50 load cells but these never functioned satisfactorily. The model was loaded with sand or mixtures of pit sand and sand with layers of coloured sand as markers. After each test, the model was soaked to stabilise $300 \mathrm{~mm}$ high slices which were sketched with the aid of a transparent reference grid.

Tests on isolated drawpoints confirmed Janelid and Kvapil's (1966) conclusions for a single drawpoint worked in isolation. However, when many drawpoints are worked at the same time, the characteristics of the draw changed dramatically as material between active draw columns was mobilised and migrated laterally into the live draw columns. Clearly, the lateral movement was due to increased stresses in the interdrawpoint areas as the weight of material in the active draw columns was transferred by friction to the peripheries of the live columns. With several live drawpoints each with its own stress field surrounding it, there would be an interaction of the stress fields, hence, the name given to this draw mechanism.

The modelling showed that in the lower draw column, there is a zone of stress interaction that induces dynamic lateral migration of material from slow drawpoints and inter-draw column areas into the live draw 
columns. The movement of material from the slower working to the faster draw columns evens out the rate of subsidence of the mass-flow zone. There is a zone of mass flow and uniform subsidence in the upper draw column above a certain height known as the height of the interaction zone (HIZ) and as the limit of uniform movement.

All these tests were just indicative of what could happen in ideal circumstances. We needed a way of applying the lessons to real block caves where the cave material had a wide range of material shapes and sizes - from boulders to finely ground rock flour generated in the draw column by grinding of rocks against each other as the block was drawn.

The writer and Dennis Laubscher (who was at that time the director of the Shabanie Mine Rock Mechanics Research Unit) discussed the issue and came up with the now well-known estimates for the IDZ diameters for a range of rock mass classes. These were not experimentally based but based on our experience at the time and were published as guidelines. This included the 1.5 factor for relating the IDZ to drawpoint spacing for interactive draw.

Much research work has been done on model tests and computer modelling to validate these guidelines. The most recent being the model test work by Castro (2007) in the large scale model at the JKMRC. He has shown that in crushed aggregate with an internal friction angle of $41^{\circ}$, interactive draw does not occur. He demonstrated that the stresses that develop at the base of the model between drawpoints are insufficient to cause yield in the inter-drawpoint material. However, assuming a lower internal friction of about $30^{\circ}$ (as in sand) and the stresses measured by Castro (2007), interactive draw becomes possible. Testing internal friction angles in run of mine block cave material is generally impractical. However, the effects of the presence of fines in coarse rock materials have been investigated in laboratory scale tests at MIT and the US Corps of Engineers Missouri River Division Laboratory. Yengi, (1981) has discussed the factors that affect the shear strength of cohesionless granular materials. Shearing resistance is increased by interlocking of fragments brought about by compaction, but reduced by the presence of fines between rock fragments. The particles in the fines matrix may slide over each other and rounded grains act as a lubricant as they are free to roll.

He states that:

"Since the inter-fragment friction angle decreases with the increase in fragment size, and void ratio, the failure structure of the materials under draw will show a comparatively lower frictional component of shearing resistance than for the same material crushed down to similar sizes".

When it is considered that there is considerable rounding and attrition of material in the draw column and every boulder is covered by a layer of fines and is increasingly able to rotate as it is rounded by attrition, it is quite conceivable that internal friction angles would be reduced to $30^{\circ}$ or less, and interactive draw remains possible. 


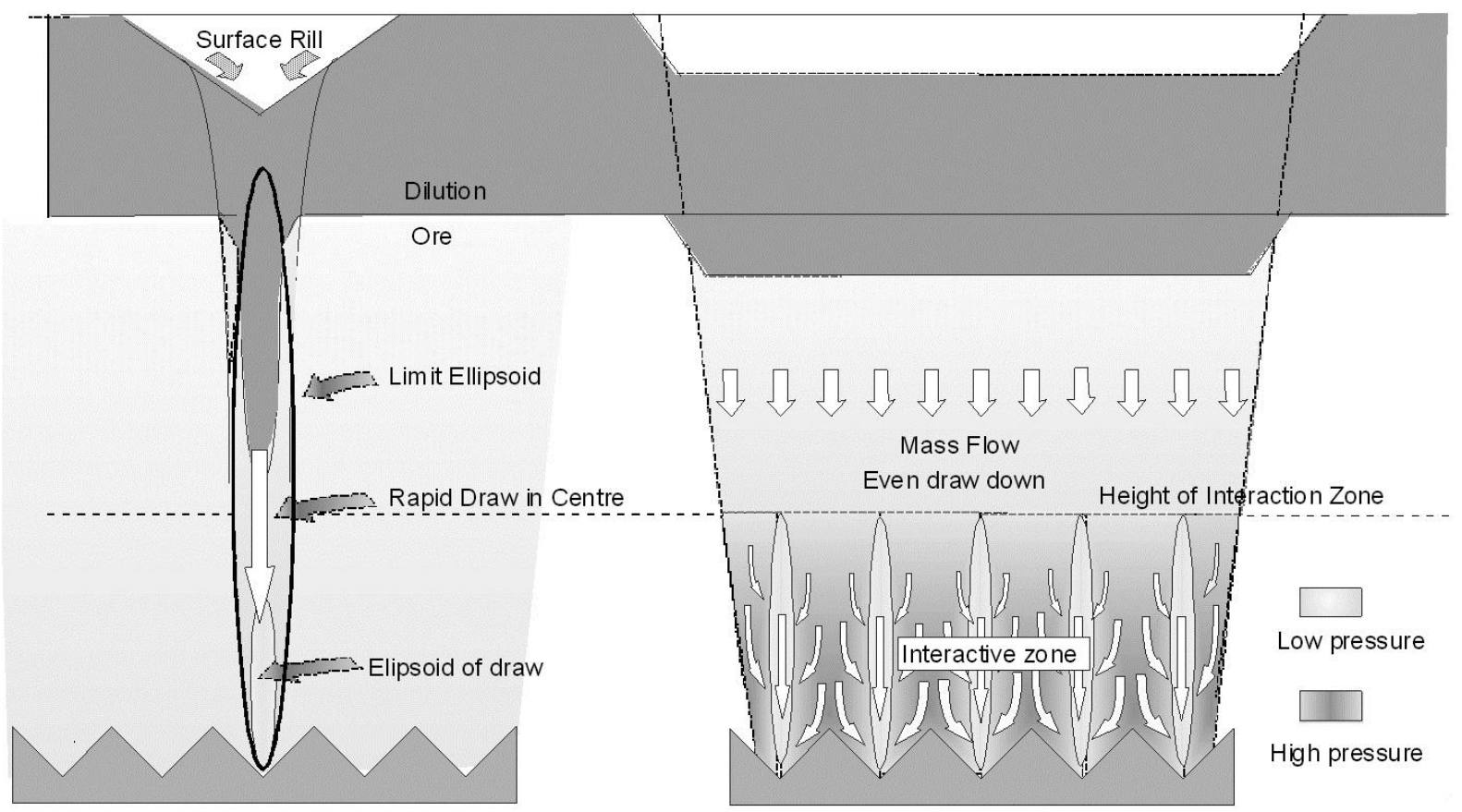

Figure 5 Granular flow mechanisms - material flow paths for drawpoints worked in isolation (left) and worked concurrently (right) where higher pressures in inter-drawpoint areas forces material into the low-pressure zones above working drawpoints

\subsubsection{Interactive draw: implications for mine design and draw management}

1. The drawpoint spacing design of an extraction level for interactive draw is also critical, too wide and the interaction will be too weak and the drawpoints will behave as isolated drawpoints. There will be consequential losses of ore between the draw columns and an early ingress of dilution. Drawpoints need to be spaced at less than 1.5 times the IDZ diameter. Measurements of stress in the JKMRC model by Castro (2007) indicates the cave material needs to have a low angle of internal friction for interaction.

2. As noted previously, the model tests by Power (2004) indicate that Laubscher's (1994) guidelines on the IDZ diameters may be underestimated.

3. For interactive draw, quite wide variations in draw rate (up to $400 \%$ ) can be tolerated, but all drawpoints need to be worked frequently to ensure that the low pressure zones above the active drawpoints are maintained. If the low pressure zones dissipate through settlement then draw will revert to isolated draw conditions.

4. With good interactive draw, the dilution entry point may be delayed to quite late in the life of the draw column, say $70 \%$ or higher, compared with $30 \%$ for isolated draw.

5. In the sand models, interactive draw levels out the draw down in the cave; variations in rates of draw are not reflected in the position of markers above the HIZ, which are drawn down the average amount of the drawpoints in the area. This indicates that slow drawpoints don't need to catch up (note that some mines do attempt to catch up when a drawpoint has been lagging behind its neighbours). If one drawpoint is worked at substantially higher rates than its neighbours, the draw ellipsoid will become much higher similar to an isolated drawpoint in interactive draw, with the expected early ingress of dilution and ore losses.

6. Although PCBC was designed on interactive draw principles, the shared zones in PCBC are dissimilar to the movement zones seen in the sand models. In interactive draw more lateral material migration occurs in the lower parts of the interactive zone whereas in PCBC this occurs in the upper reaches. Nevertheless, PCBC is being used to calculate production tonnages and grade forecasts. 
7. As for gravity flow, drawpoints that are relatively slowly drawn have contributed tonnage to their neighbouring drawpoints. Attempting to catch up may introduce dilution early.

8. When a drawpoint is worked faster than its neighbours, it will behave like an isolated drawpoint and it will draw in material from the shared overlap zones of its neighbours. The height of remaining ore in the draw column will be higher than the overdrawn tonnage may suggest.

\subsection{Void diffusion}

The third of these flow mechanisms is known as stochastic flow, probabilistic flow and void diffusion. The term void diffusion (VD) is preferred as it conveys an easily imagined dynamic picture of voids diffusing through the cave material by filling, collapsing and reforming at successively higher elevations. The mechanism has been investigated and extensively computer modelled as a stochastic process by a number of researchers. Attempts have been made in glass-fronted boxes to investigate the effects of larger angular particles on the draw behaviour, but the characteristics of the draw have been more difficult to observe and interpret, and certainly more difficult to illustrate in diagrams. Confirmation of the mechanism has come from two extensive marker experiments in sublevel caving operations at Grangesberg and Kiruna mines (LKAB) in Sweden. Recent marker experiments at Ridgeway Mine (Power, 2004) and Perseverance Mine (Szwedzicki and Cooper, 2007) have indicated very similar modes of material flow.

In the LKAB experiments, Gustafsson (1998) found that the recovery of markers did not conform to the accepted ellipsoid of draw. They indicated an irregular 'draw body' shaped like a hand with fingers extending upwards, some into the waste left by the previous ring. When the ring was fired and drawn, alternating runs of ore and waste indicated a changing pattern of draw, with some markers from higher up in the ring being recovered before lower markers. Gustafsson believes that these indicate transient voids that were filled by material from above or one or both sides, and reform a little higher up above, to one side or another of the filled void. He modelled the draw using a probabilistic function that determined whether the void was filled from above or to one side or another. By applying a modifying flow factor to the finer and more mobile waste, he reproduced the runs of waste and ore observed in the experiments.
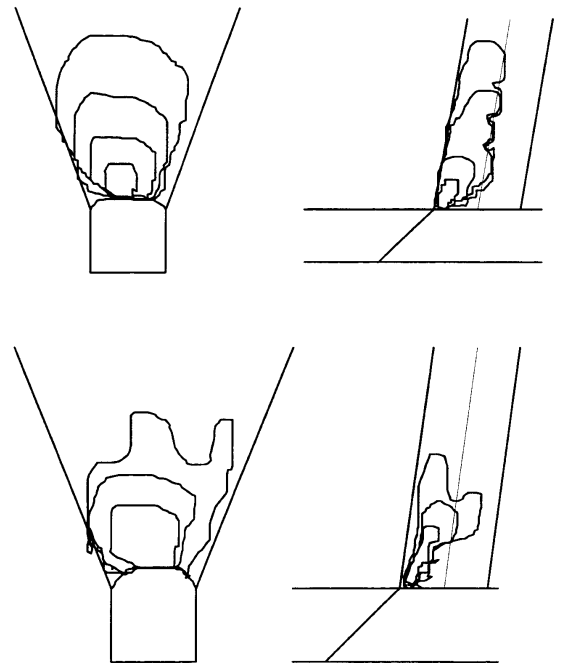

Figure 6 Gustafsson's (1998) 'palm and finger' draw body shapes from full scale marker experiments at Kiruna Mine 

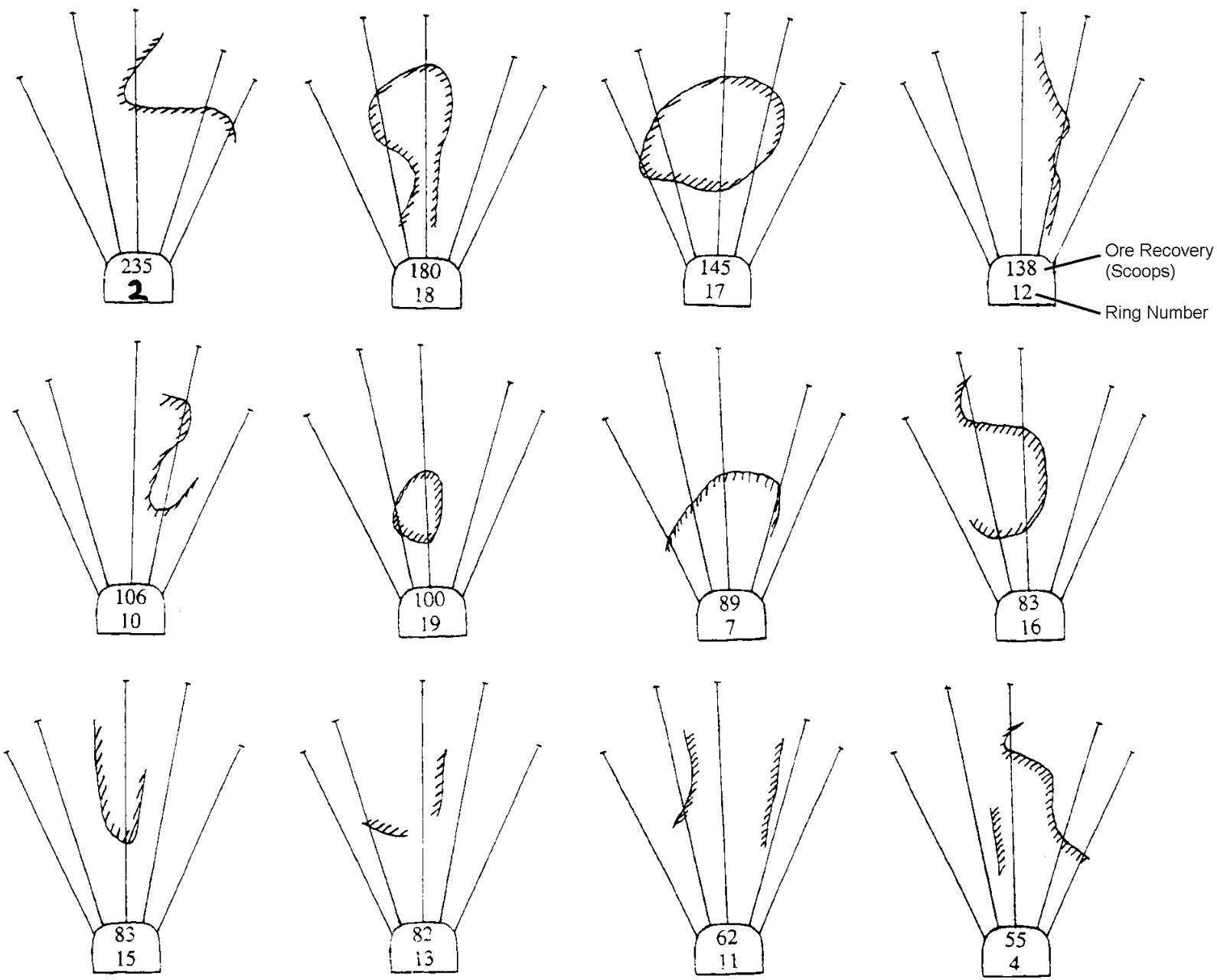

Figure 7 Some draw bodies from Gustafsson's (1998) marker experiments at Kiruna Mine

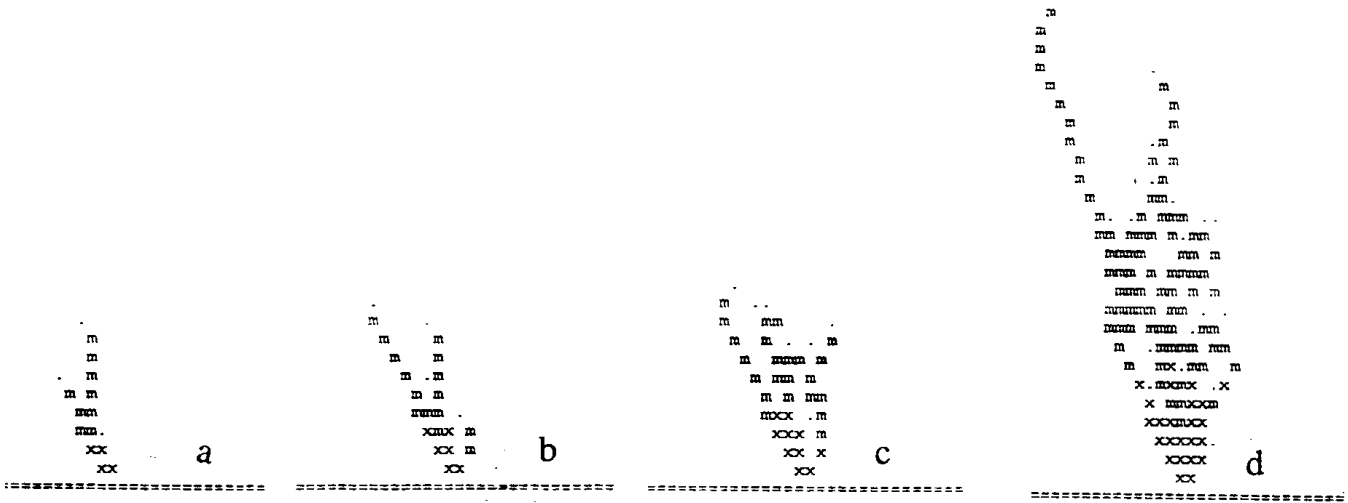

Figure 8 Draw body shapes from computer modelling: a) 6 blocks removed; b) 10 blocks removed; c) 16 blocks removed; d) 33 blocks removed

In block caving, the hypothesis is that transient voids form above the drawpoint, collapse, and reform as in the sublevel caving experiments. The voids are partially filled with material from the sides or they collapse and are filled from above, reforming a little higher up, and the process repeats itself. Fine non-cohesive or loose material may fill a cavity even as it develops. While some voids may coalescence, it is expected that generally the voids would split and become smaller and probably more stable. At some elevation in the draw 
column, the effect of numerous voids from many drawpoints is to destabilise adjacent voids thus favouring vertical flow and limiting the faster flow of fine material. This effectively transforms the draw mechanism into mass flow.

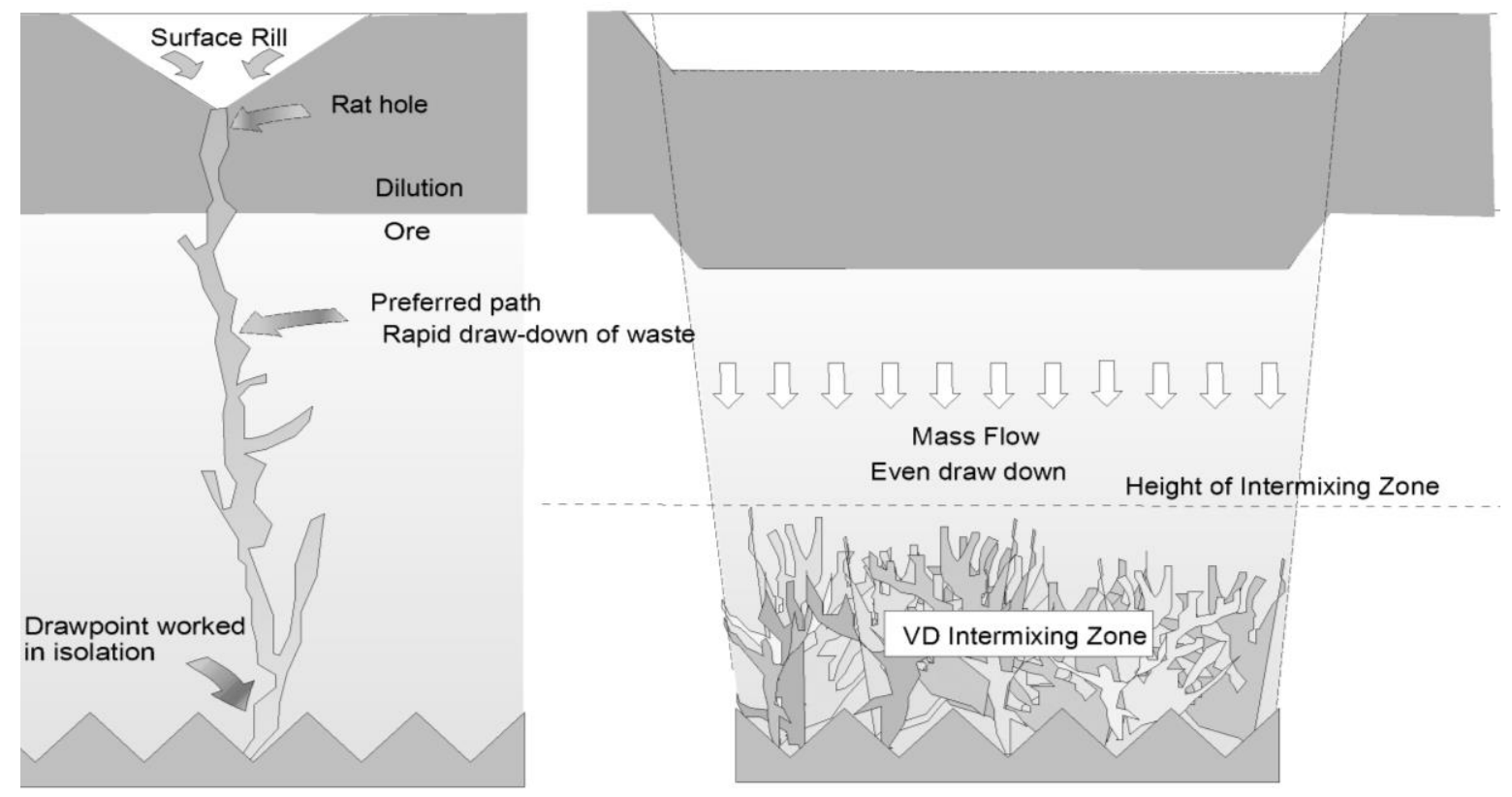

Figure 9 VD mechanisms - the formation of preferred channel leading to ratholing for a drawpoint worked in isolation (left) and overlapping of multiple palm and finger draw bodies when drawpoints worked concurrently (right)

However, if a drawpoint is worked in isolation, the passage of successive voids from the same drawpoint will form a zone of less dense, more mobile material above the drawpoint while compacting the surrounding material. 'Piping' occurs when a succession of cavities works its way through the caved material to surface. Once the path is established and filled with mobile fine material, it becomes a preferred draw-down channel that can pull dilution deep into the ore.

\subsubsection{VD draw: implications for mine design and draw management}

1. Intuitively one might expect that drawpoint spacing would be critical in designing for void diffusion draw. At this stage there are no rules of thumb and distinct element modelling is not quite ready yet to give us answers. It may be possible to develop some ideas from the sublevel caving marker test of Gustafsson (1998) and Power (2004).

2. The interpretation of VD suggests that with even and regular working of all drawpoints, the dilution entry point may be delayed, as in the other mechanisms, until quite late in the life of the draw column. However, if the overlying dilution is fine and mobile, it will report in the drawpoint early whatever draw mechanism is active.

3. The shared zones in PCBC may differ from the overlap of the draw bodies in this postulated mechanism, but at this stage PCBC is probably as good as any other package.

\section{Conclusions}

The knowledge base on block caving and in draw control is growing rapidly and some of it seems to be contradictory. It is concluded that three flow mechanisms may operate in a block cave under draw at different times or at different places at the same time. Most workers in the field agree that it is best to maintain an even rate of draw from all drawpoints, and that it is essential to track the tonnages drawn from each drawpoint and to adjust the short-term scheduled rates of draw to achieve the desired even draw down. This is most often done using a cave management system or cave production scheduling programme. While 
there are common features in the three draw mechanisms, there are also differences to which need to be considered when scheduling production.

\section{References}

Alfaro, A. and Saavedra, J. (2004) Predictive models for gravitational flow, in Proceedings MassMin 2004 , A. Karzulovic and M. Alvaro (eds), 22-25 August, Santiago, Chile, Instituto de Ingenieros de Chile, Santiago pp. 179-184.

Bell, N.J.W. (1992) Technical note on M/4e draw markers, African Associated Mines, Group report.

Brown, E.T. (2003) Block Caving Geomechanics, JKMRC Monograph Series on Mining and Mineral Processing 3, Julius Kruttschnitt Mineral Research Centre, University of Queensland, Brisbane, 515 p.

Bull, G. and Page, C.H. (2000) Sublevel Caving - Today's dependable low cost 'ore factory', in Proceedings MassMin 2000, G. Chitombo (ed), 29 October to 2 November 2000, Brisbane, Australia, Australasian Institute of Mining and Metallurgy, Melbourne, pp. 537-556.

Castro, R.L. (2007) Study of the mechanisms of gravity flow for block caving, Thesis (PhD), University of Queensland, $314 \mathrm{p}$.

Castro, R.L. Gonzalez, F. and Arancibia, E. (2009) Development of gravity flow model for the evaluation of drawpoint spacing for block/panel caving, Journal of the South African Institute of Mining and Metallurgy, 2009, pp. 393-400.

Diering, T. (2000) PC-BC: A Block cave Design and Draw Control System, in Proceedings MassMin 2000 , G. Chitombo (ed), 29 October to 2 November 2000, Brisbane, Australia, Australasian Institute of Mining and Metallurgy, Melbourne, pp. 469-484.

Guest, A.R. (2007) The difference between interaction and interactive draw, in Proceedings 1st International Symposium on Block and Sub-Level Caving, Journal of the Southern African Institute of Mining and Metallurgy, pp. $123-132$.

Gustafsson, P. (1998) Waste rock content variations during gravity flow in sublevel caving - analysis of full scale experiments and numerical simulations, Doctoral Thesis 1998:10, Luleå University of Technology, Luleå, Sweden, $247 \mathrm{p}$.

Heslop, T.G. (1983) The Application of Interactive Draw Theory to Draw Control Practice in Large Chrysotile Asbestos Mines, Mining and Metallurgical Operations in Zimbabwe, June 1983, Harare: Institution of Mining and Metallurgy Zimbabwe Section, 1983, Vol. III, pp. 290-313.

Janelid, I. and Kvapil, R. (1966) Sublevel caving, International Journal of Rock Mechanics and Mining Science, Pergamon Press, Vol. 3, pp. 129-153.

Jolley, D. (1968) Computer simulations of the movement of ore and waste in an underground mining pillar, Canadian Institute Mining Metallurgy Transactions, Vol. 61, No. 675, pp. 854-859.

Laubscher, D. (1994) Cave mining - the state of the art, Journal of the South African Institute of Mining and Metallurgy, pp. 279-293.

Laubscher, D. (2000) Block Caving Manual, International Caving Study Report, JKMRC and Itasca Consulting Group Inc., Brisbane.

Marano, G. (1980) The interaction between adjoining draw points in free flowing materials and its application to mining, Chamber of Mines Journal, Zimbabwe Chamber of Mines, Harare, Zimbabwe, Vol. 22, No. 5.

McNicholas, F.S., Rogers, V.C. and Walker, S. (1946) An experimental study of caving and drawing large orebodies, American Institute of Mining, Metallurgical and Petroleum Engineers Transactions, Chicago meeting, February, Vol. 163, pp. 156-197.

Power, G.R. (2004) Modelling granular flow in caving mines: large scale physical modelling and full scale experiments, Thesis (PhD), University of Queensland, $283 \mathrm{p}$.

Susaeta, A. (2004a) Theory of gravity flow (Part 1), in Proceedings MassMin 2004, A. Karzulovic and M. Alvaro (eds), 22-25 August, Santiago, Chile, Instituto de Ingenieros de Chile, Santiago, pp. 167-172.

Susaeta, A. (2004b) Theory of gravity flow (Part 2), in Proceedings MassMin 2004, A. Karzulovic and M. Alvaro (eds), 22-25 August, Santiago, Chile, Instituto de Ingenieros de Chile, Santiago, pp. 173-178.

Szwedzicki, T. and Cooper, R. (2007) Ore flow and fragmentation at Perseverance Mine, in Proceedings 1st International Symposium on Block and Sub-Level Caving, Southern African Institute of Mining and Metallurgy, pp. 133-146.

Yengi, L.I. (1981) Analysis of bulk flow of materials under gravity caving process, Part 2 Theoretical and physical modelling of gravity flow of broken rock, Colorado School of Mines Quarterly, Vol. 75, No. 3. 
